This is a self-archived version of an original article. This version may differ from the original in pagination and typographic details.

Author(s): Kytöviita, Minna-Maarit; Olofsson, Johan

Title: Idiosyncratic responses to simulated herbivory by root fungal symbionts in a subarctic meadow

Year: 2021

Version: Published version

Copyright: (c) 2021 the Authors

Rights: $C C$ BY 4.0

Rights url: https://creativecommons.org/licenses/by/4.0/

Please cite the original version:

Kytöviita, M.-M., \& Olofsson, J. (2021). Idiosyncratic responses to simulated herbivory by root fungal symbionts in a subarctic meadow. Arctic, Antarctic and Alpine Research, 53(1), 80-92. https://doi.org/10.1080/15230430.2021.1878738 


\section{Arctic, Antarctic, and Alpine Research}

An Interdisciplinary Journal

\section{Idiosyncratic responses to simulated herbivory by root fungal symbionts in a subarctic meadow}

\section{Minna-Maarit Kytöviita \& Johan Olofsson}

To cite this article: Minna-Maarit Kytöviita \& Johan Olofsson (2021) Idiosyncratic responses to simulated herbivory by root fungal symbionts in a subarctic meadow, Arctic, Antarctic, and Alpine Research, 53:1, 80-92, DOI: 10.1080/15230430.2021.1878738

To link to this article: https://doi.org/10.1080/15230430.2021.1878738

\section{(c) 2021 The Author(s). Published with license by Taylor \& Francis Group, LLC.}

\section{Published online: 10 Mar 2021.}

Submit your article to this journal $₫$

Q View related articles $₫$

View Crossmark data $\nearrow$ 


\title{
Idiosyncratic responses to simulated herbivory by root fungal symbionts in a subarctic meadow
}

\author{
Minna-Maarit Kytöviita $\mathbb{D D}^{\mathrm{a}}$ and Johan Olofsson $\mathbb{D}^{\mathrm{b}}$ \\ ${ }^{a}$ Department of Environmental and Biological Science, Jyvaskyla University, Jyväskylä, Finland; bepartment of Ecology and Environmental \\ Science, Umeå University, Umeå, Sweden
}

\begin{abstract}
Plant-associated fungi have elementary roles in ecosystem productivity. There is little information on the interactions between arbuscular mycorrhizal (AM) fungal symbiosis, fine endophytic (FE) and dark septate endophytic (DSE) fungi, and their host plants in cold climate systems. In particular, the environmental filters potentially driving the relative abundance of these root symbionts remain unknown. We investigated the interlinkage of plant and belowground fungal responses to simulated herbivory (clipping, fertilization, and trampling) in a subarctic meadow system. AM and FE frequency in the two target plant roots, Potentilla crantzii and Saussurea alpina, was unaffected by simulated herbivory, highlighting the importance and resilience of arbuscule forming mycorrhizas in a range of environmental conditions. Fertilization and trampling increased DSE colonization in $P$. crantzii roots although generally $P$. crantzii performance was reduced in these plots. The idiosyncratic responses by DSE fungal frequency in the two host plants in our experiment indicate that the host plant identity has a pivotal role in the DSE fungus-plant outcome. DSE fungal frequency did not respond to environmental manipulations in a manner similar to arbuscular mycorrhizas, suggesting that they have a different role in plant ecology.
\end{abstract}

\section{ARTICLE HISTORY}

Received 4 May 2020

Revised 12 November 2020

Accepted 13 January 2021

\section{KEYWORDS}

Arbuscular mycorrhiza; dark septate endophytes; fine endophytes; grazing

\section{Introduction}

Plant-herbivore and plant-fungi interactions are central in northern ecosystem functions. However, the interactions between these two processes are seldom considered (but see Bethlenfalvay and Dakessian 1984; Gehring and Whitham 2002; Murray, Frank, and Gehring 2011). The predominant grazers, reindeer and caribou, affect plant community structure and ecosystem processes in subarctic ecosystems in a fundamental way (Olofsson, Stark, and Oksanen 2004; van der Wal 2006). Grazers affect microbial and plant performance by increasing readily available nutrients through urine and feces and by increasing soil temperature (Olofsson and Oksanen 2002; Olofsson, Stark, and Oksanen 2004; van der Wal and Brooker 2004; Barthelemy, Stark, and Olofsson 2015). Ecosystem effects of herbivory are modeled through grouping plants into functional groups and assuming high similarity within a functional group. However, plants may respond to herbivory in a speciesspecific way (Riach et al. 2015; Richards et al. 2015). Plant species also have idiosyncratic effects on soil, giving rise to species-specific ecosystem effects (Eisenhauer et al. 2011; Kos et al. 2015; Heinen et al. 2018). Furthermore, plants house a large variety of fungal symbionts that directly affect plant performance in a species-specific way (Munkvold et al. 2004) and that may also respond to grazing. Some fungal symbionts act synergistically with the host plant, whereas others may make contrasting contributions to plant nutrition as well as carbon and nitrogen turnover in the soil (Read and Perez-Moreno 2003).

The majority of herbaceous species form intensive symbiotic relationships with arbuscular mycorrhizal (AM) fungi (Brundrett 2002). AM symbiosis is generally a mutualistic system where the plants deliver photosynthates to the AM fungi and receive nutrients, water, and protection against root herbivores in return. AM fungi are obligatorily symbiotic, lack saprophytic capacities, and depend solely on the host delivery of carbon. The carbon consumption by AM fungi can be a substantial part of plants' carbon budget. Under laboratory conditions, AM fungi have consumed up to

CONTACT Minna-Maarit Kytöviita minna-maarit.kytoviita@jyu.fi @ Department of Environmental and Biological Science, Jyvaskyla University, PO Box 35, FIN 40014, Finland. 
30 percent of plant total net photosynthetic gains (Drigo et al. 2010). The costs are unlikely to be smaller under field conditions because fungal hyphae are constantly consumed by fungal-feeding soil animals (Johnson et al. 2005). As a result of carbon allocation to mycorrhizas, mycorrhizal plants have proportionally smaller roots than nonmycorrhizal plants (Brundrett 2002). Despite considerable carbon costs, it is generally thought that association with mycorrhizal fungi confers plants some benefit, usually in the form of improved nutritional status, growth, and reproductive output. AM symbiosis increases $\mathrm{P}$ and $\mathrm{N}$ capture and photosynthesis in low Arctic herbs under laboratory conditions (Ruotsalainen and Kytöviita 2004; Kytöviita and Ruotsalainen 2007). Generally, AM symbiosis has been shown to improve tolerance to drought (Augé 2001) and resistance to antagonists (Pozo and Azcón-Aguilar 2007) and increase plant reproduction by increasing flower number (Lu and Koide 1994) and seed quality (Nuortila, Kytöviita, and Tuomi 2004). Plant interactions with their symbiotic AM fungi play a key role in plant competition (Pietikäinen and Kytöviita 2007; Scheublin, van Logtestijn, and van der Heijden 2007) and, consequently, vegetation composition (Hartnett and Wilson 1999) and ecosystem productivity (Klironomos et al. 2000).

In addition to traditional AM structures, it is possible to visually separate intensively staining thin, meandering fungal structures known as fine endophytes (Orchard, Standish et al. 2017). The fine endophyte (FE) colonization type has been traditionally known as Glomus tenue (e.g., Hall 1977), but in light of recent evidence the species forming FE colonization may belong to the subphylum Mucoromycotina (Orchard, Hilton et al. 2017) in the genus Planticonsortium (Walker, Gollotte, and Redecker 2018). FE colonization has been reported worldwide (Orchard, Standish et al. 2017). FE colonization is documented in liverworts (Bidartondo et al. 2011), hornworts (Desirò et al. 2013), ferns (Hoysted et al. 2019), and seed plants (Orchard, Standish et al. 2017). When in symbiosis with liverworts, the fine endophytic symbiosis functioned differently to AM symbiosis in resource exchange with the host (Field et al. 2019). Although there are reports of FE colonization in various host plant species in agricultural and more natural habitats (Orchard, Standish et al. 2017), the response of FE colonization to environmental manipulations is very rarely reported. Therefore, the ecology of FE colonizing fungi and their role in vascular host plants remain elusive.

In cold climates, plant roots are intensively colonized by dark, septate, nonstaining endophytic fungi (DSE) belonging to the phylum Ascomycota (Addy, Piercey, and Currah 2005). DSE fungi have been shown to possess significant degradative capacities (Caldwell, Jumpponen, and Trappe 2000; Knapp and Kovacs 2016) and consequently may mineralize soil organic matter and grow in soil independent of any host plant. DSE colonize herbs, grasses, and sedges in cold climates (Zubek et al. 2009; Bueno de Mesquita et al. 2018). Unlike AM, DSE do not produce symbiosis-specific structures. Though the presence of DSE fungi in plant roots has inspired many reviews (Jumpponen 2001; Mandyam and Jumpponen 2005; Newsham, Upson, and Read 2009; Newsham 2011), the role of DSE fungi in plant ecology is unknown. Crucially, manipulative experiments and hypotheses on DSE are mainly lacking. For example, it is unknown whether DSE fungi are mutualistic like AM or whether they are saprophytic fungi in the soil, mineralizing soil nutrients in the rhizosphere and occupying plant roots as commensals. Even if the latter most parsimonious explanation for the occurrence of DSE fungi in roots were the case, DSE fungi are special in their ability to grow inside plant roots without provoking plant defense.

Theoretically, herbivory could negatively affect plant resource allocation to root fungal symbionts because herbivory is likely to reduce the amount of photosynthates available to the root system and the symbiont (Gehring and Whitham 2002). In addition, increased soil nutrient availability theoretically lessens the difference between root and fungal uptake efficiency and should lead to reduced plant investment in nutrient uptake through root symbionts (Tuomi, Kytöviita, and Härdling 2001; Corkidi et al. 2002). Mycorrhizal symbiosis is an adaptation to enhance plant nutrient acquisition and the symbiosis may become unnecessary at high nutrient levels (Tuomi, Kytöviita, and Härdling 2001). However, no clear relationship between increased soil nutrient levels and reduced arbuscular mycorrhizal incidence has ever been shown in natural ecosystems, indicating that under natural conditions soil nutrient levels are not limiting mycorrhizal benefit to the host plant. Trampling by large mammalian herbivores compacts the soil (Donkor et al. 2002) and reduces soil fungal abundance (Sørensen et al. 2009). On the other hand, trampling decreases the moss layer (van der Wal and Brooker 2004) and may therefore increase soil summer temperatures, which should have positive effects on mycorrhizas in cold ecosystems (Kytöviita 2005; Kytöviita and Ruotsalainen 2007). In the field, grazing is reported to decrease (Bethlenfalvay and Dakessian 1984), have no effect (Lugo, Maza, and Cabello 2003; Dhillion and Gardsjord 2004; Pietikäinen, Kytöviita, and Vuoti 2005), or increase (Eom, Wilson, and Hartnett 2001; Gehring, Wolf, and Theimer 2002) the frequency 
of AM fungal structures in plant roots. Biotic interactions are complex. Defoliation may affect the amount and functioning of AM in plant roots but, in return, AM may affect the plant responses to herbivory through affecting plant nutritional status (Koide 1991) and chemical defense (Pozo and Azcón-Aguilar 2007). In seeking general rules that predict plant-AM and -DSE fungal interactions, we investigated the $\mathrm{AM}, \mathrm{FE}$, and DSE and host plant responses to resource manipulations under field conditions.

Because of their active role in plant resource acquisition, it is logical to argue that arbuscular mycorrhizal frequency should reflect resource availability (Gehring and Whitham 2002). However, we suggest an alternative, equally logical scenario: Because mycorrhizas have an elementary role in plant resource acquisition and defense, they should be maintained even under changing environmental conditions as long as the host plant is growing and requires significant quantities of nutrients. There seems to be no clear general rule emerging as to how grazing affects the amount of fungal structures in plant roots and hence most likely their functions (Barto and Rillig 2010). In particular, there is scant information on the response of DSE and FE fungi to environmental manipulations. Knowledge on DSE and FE fungal responses to environmental manipulations could elucidate their potential ecological role. For instance, if they respond to environmental changes in a manner similar to AM fungi, one could assume that their abundance is governed by the same factor or factors. Most experiments on effects of herbivory only examine the effect of artificial defoliation, and, for example, the effects of trampling and enhanced nutrient levels associated with natural herbivory have received much less attention.

In this article, we present a full-factorial subarctic field experiment where the effects of herbivory are separated into singular effects of loss of foliage, trampling, and increased nutrient level or factorial combinations of these. We investigated the root fungal frequency and host plant response to the simulated grazing. We expected that the fungal responses should mirror positive host plant responses to the treatments if the fungi are indispensable in resource acquisition for the host.

We specifically hypothesized that (1) because defoliation removes nutrients from plant aboveground parts and consequently defoliated plants have an increased need for nutrients, defoliation should not negatively affect the AM symbiont abundance in plant roots because AM are the main pathway for nutrient uptake; (2) because trampling disturbs the fungal hyphae exploring soil for water and nutrients, trampling should reduce the abundance of AM, FE, and DSE fungi in soil and plant roots; (3) because subarctic soil microbes are nutrient limited (Schimel and Bennett 2004) and AM fungi have been shown to be $\mathrm{N}$ and $\mathrm{P}$ limited in nutrient poor soils (Treseder and Allen 2002), moderate fertilization would increase AM, FE, and DSE fungal frequency in soil and plant roots; and (4) if DSE ecology is similar to that of AM (Ranelli et al. 2015), their abundances correlate in plant roots.

\section{Material and methods}

\section{Plant material}

We chose Potentilla crantzii (Rosaceae) and Saussurea alpina (Asteraceae) as the target host plants for this study. Potentilla is a perennial, nonclonal plant that occurs in mountains in North America and southern and central Europe but is increasingly common in meadows in northern Europe. Saussurea is a perennial, nonclonal, arctoalpine plant that has circumpolar distribution in cold climate meadow habitats. Both species form arbuscular mycorrhizal symbiosis under natural conditions (Wang and Qiu 2006) and are readily consumed by reindeer (Skjenneberg and Slagsvold 1968; pers. obs., M-MK \& JO).

\section{Field setup}

The experiment was established in 2002 on a northfacing slope of the valley Kärkevagge in Abisko, situated 630 to 720 m.a.s.l. in northern Sweden $\left(25^{\prime} 68^{\circ} \mathrm{N}, 19^{\prime} 18^{\circ}\right.$ E). The vegetation is dominated by graminoids, such as Deschampsia cespitosa, Carex bigelowii, Poa alpina, and Festuca ovina, and forbs, such as Potentilla crantzii, Saussurea alpina, Alchemilla glomerulans, Trollius europaeus, and Bistorta vivipara. The ground layer is covered by an almost continuous layer of mosses Pleurozium schreberi and Hylocomium splendens. At the nearest weather station $(6 \mathrm{~km}$ west of the field site at 517 m.a. s.l.) the mean annual temperature is $-1.4^{\circ} \mathrm{C}$ and the mean annual precipitation $848 \mathrm{~mm}$.

The experimental setup consisted of three treatments in a full-factorial design: defoliation (no defoliation vs. defoliation), fertilization (no fertilization vs. fertilization using NPK solution), and trampling (no trampling vs. trampling). Treatment combinations were randomly allocated to plots $(1.5 \mathrm{~m} \times 1.5 \mathrm{~m})$ in five replicate blocks and subjected to the treatments once a year in 2002 to 2004. In defoliated plots, all vegetation was cut to a height of $2 \mathrm{~cm}$ above the ground or moss layer early in the summer (between 3 and 11 July) and the cut material was removed. The fertilizer $(2 \mathrm{~g} \mathrm{~N}, 0.3 \mathrm{~g}$ P, and $1.4 \mathrm{~g} \mathrm{~K} \mathrm{~m}^{-2}$ ) was dissolved in $10 \mathrm{~L}$ of water and added to plots immediately after defoliation (between 5 
and 12 July). Those plots that were not subjected to fertilization received $10 \mathrm{~L}$ of pure water. The fertilizer application was aimed to match the amount of nutrients removed by defoliation, but because plant production was lower than expected, the added amount of $\mathrm{N}$ exceeded the amount removed by defoliation (1.5 and $1.3 \mathrm{~g} \mathrm{~N} \mathrm{~m}^{-2}$ from the fertilized and nonfertilized plots, respectively; Olofsson and Shams 2007) and thus led to an unintended net addition of $\mathrm{N}$ into the grassland. Trampling was simulated by dropping a pole (12 $\mathrm{kg}$ and $80 \mathrm{~mm}$ in diameter) from a height of $40 \mathrm{~cm}$ on the vegetation using an intensity of 100 pole drops per square meter. The pressure from the pole is similar to that from a reindeer hoof and the frequency of the simulated trampling was set to mimic the trampling observed by trampling indicators in natural settings (Egelkraut et al. 2020). The trampling treatment was applied after defoliation and fertilization (between 7 and 12 July). Consequently, there were eight treatment combinations and five plots in each, for a total of forty plots.

\section{Analysis of fungal parameters}

Individual Potentilla and Saussurea plants were collected from the plots in beginning of August 2005. We aimed to collect at least three individual Potentilla and Saussurea in each of the forty plots. However, the natural abundance of the target species varied and this was not possible in all plots. On average four individuals of each species per plot were collected, but out of forty plots, in three plots only two Saussurea were collected, in two plots only one Saussurea was collected, and in one plot only two Potentilla were collected. This deviation from target numbers was random and not related to the treatments. Altogether 173 Potentilla and 164 Saussurea individuals were collected. The plants with their root systems were collected from the field by cutting about $12 \mathrm{~cm} \times 12 \mathrm{~cm} \times 12 \mathrm{~cm}$ soil around the shoots. The soil blocks were transferred to the laboratory and the roots of individual plants were carefully washed to remove soil. For each plant, between five and ten root fragments of $2 \mathrm{~cm}$ length were cut from the root system and stored in 50 percent ethanol until analyzed for fungal colonization intensity. Fungal colonization intensity in the roots was assessed under a light transmission microscope using the gridline intersection method (McGonigle et al. 1990) after clearing the roots with $\mathrm{H}_{2} \mathrm{O}_{2}$ and $\mathrm{KOH}$ and staining with trypan blue (Phillips and Hayman 1970). For each root fragment, ten intersections were scored for the presence of classic arbuscular mycorrhizal structures (hyphae, arbuscules, vesicles), collectively those of fine endophytes, dark septate endophytic fungi, and yeasts. FE structures were identified because of their very thin and intensively staining hyphae that form a characteristic morphology (Gianinazzi-Pearson et al. 1981). DSE fungi are characterized by formation of nonstaining, dark, pigmented, and septate hyphae and sclerotia in plant roots. Yeasts were classified as trypan blue staining unicellular fungi. Root colonization by other fungi was negligible. Roots were scored at $100 \times$ magnification, or occasionally at higher magnification when necessary.

\section{Analysis of plant frequency, shoot phosphorus and nitrogen concentrations}

The frequency of Potentilla and Saussurea on the plots was scored in July in 2003, 2004, and 2005 using a $50 \mathrm{~cm} \times 50 \mathrm{~cm}$ frame with $10-\mathrm{cm}$ squares positioned in the middle of the plot. The frequency of the species is the number of squares occupied by the species. Shoot material of Potentilla and Saussurea was collected in beginning of August 2005. All plant material from a $0.25 \mathrm{~m} \times 0.25 \mathrm{~m}$ subplot was collected and a subsample of this was used for chemical analyses. Dried and milled plant material was acid digested using the Paar001H program in the Paar Physica multiwave sample preparation system (PerkinElmer) and plant $\mathrm{P}$ content was analyzed following the procedure described in John (1970). P concentration was measured as absorbance at $882 \mathrm{~nm}$ (UV-160A, Shimadzu). Leaf carbon and nitrogen contents were analyzed using an elemental analyzer (PerkinElmer 2400 Series II CHNS/O-analyzer).

\section{Statistical analyses}

Plants in one plot are likely not to be independent of each other and therefore mean values per plot were used as statistical variates. Consequently, $N=40$ and $n=5$ for all analyses. To test plant frequency responses to treatments over the years, a repeated measures analysis of variance (ANOVA) was conducted. To test for statistically significant differences due to treatments in the nutrient concentration and colonization parameters, a full-factorial ANOVA including interactions was conducted. The factors defoliation, trampling, and fertilization were considered fixed in the model. Homogeneity of variance was tested with Levene's test. Correlations between the frequency of different fungal structures were estimated with Pearson's correlation analysis. All statistical analyses were conducted using SPSS v24 (IBM 2016). 


\section{Results}

The target plants had opposite responses to different aspects of grazing in terms of plant frequency in the plots (Figure 1, Table 1). Fertilization decreased Potentilla mean abundance, whereas cutting significantly mitigated the negative effect of fertilization (Figure 1, Table 1). Cutting had clear negative effects
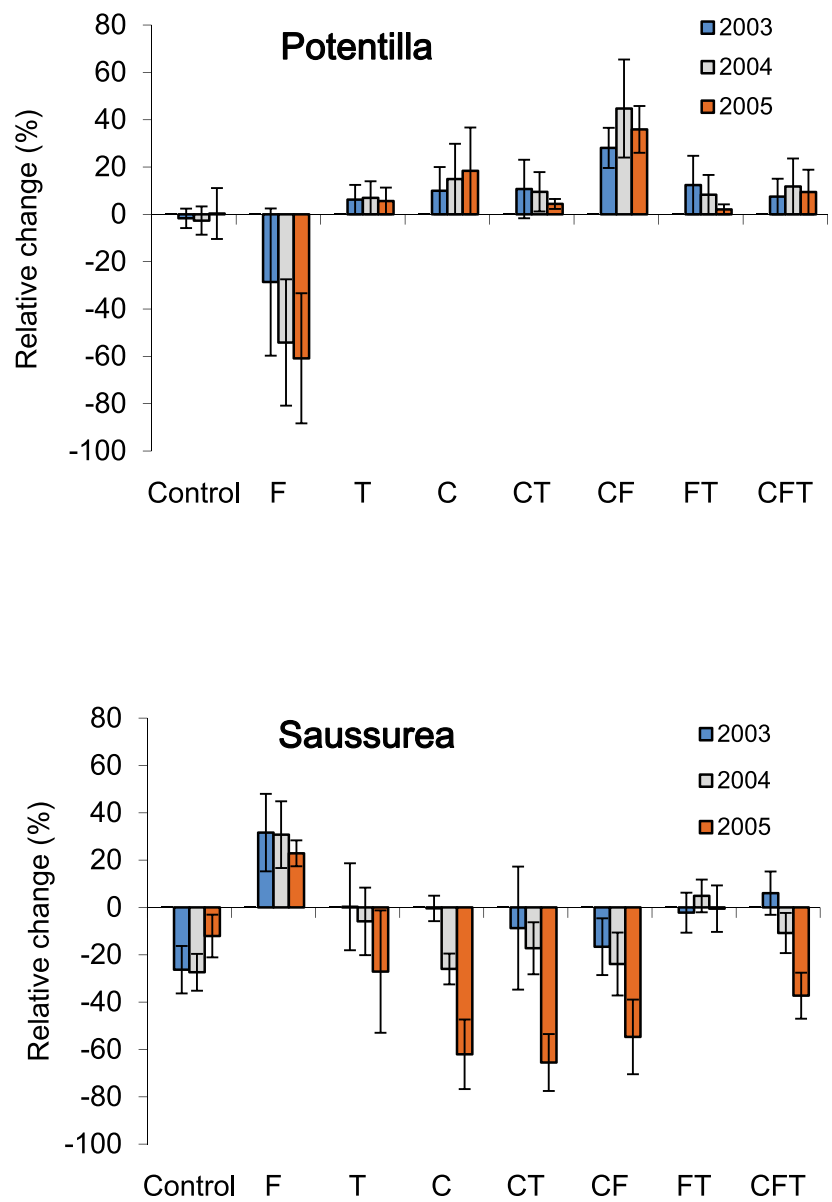

Figure 1. Relative annual change in Potentilla crantzii and Sassurea alpina frequency in the field plots subjected to fertilization, trampling, and cutting treatments in a full-factorial design ( $N=40$ for Potentilla and $N=39$ for Saussurea). Fertilization (F), Trampling (T) and Cut (C).
Table 1. Repeated measures ANOVA results on Potentilla crantzii and Saussurea alpina frequency on the plots exposed to fertilization, trampling, and cutting treatments in a full-factorial design over the years 2002 to 2004 .

\begin{tabular}{|c|c|c|c|c|}
\hline \multicolumn{5}{|l|}{ Source of variation } \\
\hline Between subjects & $\mathrm{df}$ & SS & $F$ value & $p$ Value \\
\hline \multicolumn{5}{|l|}{ Potentilla } \\
\hline Fertilization (F) & 1 & 159.8 & 1.544 & .226 \\
\hline Trampling (T) & 1 & 70.5 & 0.681 & .417 \\
\hline Cutting (C) & 1 & 15.8 & 0.154 & 699 \\
\hline $\mathrm{CT}$ & 1 & 39.4 & 0.381 & .543 \\
\hline CF & 1 & $1,451.3$ & 14.023 & $.001^{* *}$ \\
\hline FT & 1 & 178.1 & 1.721 & .202 \\
\hline CFT & 1 & 7.7 & 0.073 & .790 \\
\hline Residual & 24 & $2,483.7$ & & \\
\hline \multicolumn{5}{|l|}{ Within subjects } \\
\hline Year & 3 & 121.6 & 9.093 & $<.001^{* * *}$ \\
\hline $\mathrm{F} \times$ Year & 3 & 15.2 & 1.137 & .340 \\
\hline$C \times$ Year & 3 & 44.9 & 3.356 & $.023 * *$ \\
\hline $\mathrm{T} \times$ Year & 3 & 160.2 & 11.98 & $<.001^{* * *}$ \\
\hline $\mathrm{F} \times \mathrm{C} \times$ Year & 3 & 32.6 & 2.44 & $.071 *$ \\
\hline $\mathrm{F} \times \mathrm{T} \times$ Year & 3 & 47.0 & 15.65 & $.019^{* *}$ \\
\hline $\mathrm{C} \times \mathrm{T} \times$ Year & 3 & 11.0 & 0.819 & .488 \\
\hline $\mathrm{F} \times \mathrm{C} \times \mathrm{T} \times$ Year & 3 & 4.2 & 0.315 & .815 \\
\hline Residual & 72 & 321.1 & & \\
\hline \multicolumn{5}{|l|}{ Saussurea } \\
\hline \multicolumn{5}{|l|}{ Source of variation } \\
\hline \multicolumn{5}{|l|}{ Between subjects } \\
\hline Fertilization (F) & 1 & 116.3 & 3.080 & $.092^{*}$ \\
\hline Trampling $(\mathrm{T})$ & 1 & 18.0 & 0.477 & .497 \\
\hline Cutting (C) & 1 & 231.1 & 6.119 & $.021^{* *}$ \\
\hline $\mathrm{CT}$ & 1 & 5.8 & 0.140 & .712 \\
\hline CF & 1 & 21.1 & 0.559 & .462 \\
\hline FT & 1 & 0.1 & 0.003 & .955 \\
\hline CFT & 1 & 0.3 & 0.007 & .932 \\
\hline Residual & 24 & 906.2 & & \\
\hline \multicolumn{5}{|l|}{ Within subjects } \\
\hline Year & 3 & 99.9 & 14.497 & $<.001^{* * *}$ \\
\hline $\mathrm{F} \times$ Year & 3 & 14.2 & 2.258 & $.089^{*}$ \\
\hline $\mathrm{C} \times$ Year & 3 & 83.1 & 13.246 & $<.001^{* * *}$ \\
\hline $\mathrm{T} \times$ Year & 3 & 7.2 & 1.146 & .336 \\
\hline $\mathrm{F} \times \mathrm{C} \times$ Year & 3 & 6.6 & 1.05 & .377 \\
\hline $\mathrm{F} \times \mathrm{T} \times$ Year & 3 & 3.8 & 0.61 & .612 \\
\hline $\mathrm{C} \times \mathrm{T} \times$ Year & 3 & 0.7 & 0.10 & .957 \\
\hline $\mathrm{F} \times \mathrm{C} \times \mathrm{T} \times$ Year & 3 & 11.2 & 1.80 & .159 \\
\hline Residual & 72 & 150.5 & & \\
\hline
\end{tabular}

and fertilization had positive effects on Saussurea abundance on the plots (Figure 1, Table 1). These responses were not reflected in a straightforward manner in the shoot nutrient concentrations (Table 2). $\mathrm{N}$ and $\mathrm{P}$ concentrations in Potentilla shoots increased with

Table 2. Nitrogen and phosphorus concentrations (\% in dry matter) in the Potentilla crantzii and Saussurea alpina shoots and the Pvalues according to the analysis of variance on the three factors (Cut, Fertilization, Trampling) and their interactions. Mean values \pm SE are shown, $\mathrm{N}=40$ for Potentilla and 39 for Saussurea.

\begin{tabular}{|c|c|c|c|c|c|c|c|c|}
\hline & \multicolumn{4}{|c|}{ Elemental concentration } & \multicolumn{4}{|c|}{ P-values } \\
\hline & $\begin{array}{c}\mathrm{N} \% \\
\text { Potentilla }\end{array}$ & $\begin{array}{c}\mathrm{N} \% \\
\text { Saussurea }\end{array}$ & $\begin{array}{c}\mathrm{P} \% \\
\text { Potentilla }\end{array}$ & $\begin{array}{c}\mathrm{P} \% \\
\text { Saussurea }\end{array}$ & $\begin{array}{c}\mathrm{N} \\
\text { Potentilla }\end{array}$ & $\begin{array}{c}\mathrm{N} \\
\text { Saussurea }\end{array}$ & $\begin{array}{c}\mathrm{P} \\
\text { Potentilla }\end{array}$ & $\begin{array}{c}\mathrm{P} \\
\text { Saussurea }\end{array}$ \\
\hline control & $2.26 \pm 0.08$ & $2.48 \pm 0.14$ & $0.196 \pm 0.011$ & $0.155 \pm 0.031$ & & & & \\
\hline Fert & $2.62 \pm 0.15$ & $2.76 \pm 0.15$ & $0.212 \pm 0.015$ & $0.221 \pm 0.022$ & $0.012^{* *}$ & 0.120 & $0.045^{* *}$ & $0.092^{*}$ \\
\hline Tramp & $2.69 \pm 0.15$ & $2.15 \pm 0.16$ & $0.177 \pm 0.012$ & $0.157 \pm 0.029$ & 0.184 & $0.023^{* *}$ & 0.094 & 0.168 \\
\hline Cut & $2.24 \pm 0.13$ & $2.47 \pm 0.17$ & $0.157 \pm 0.007$ & $0.172 \pm 0.020$ & 0.195 & 0.408 & 0.058 & 0.278 \\
\hline $\mathrm{CT}$ & $2.19 \pm 0.21$ & $2.17 \pm 0.05$ & $0.163 \pm 0.009$ & $0.141 \pm 0.021$ & 0.373 & 0.661 & 0.161 & 0.282 \\
\hline $\mathrm{CF}$ & $2.09 \pm 0.16$ & $2.68 \pm 0.11$ & $0.192 \pm 0.009$ & $0.209 \pm 0.026$ & 0.288 & 0.362 & 0.311 & 0.269 \\
\hline $\mathrm{FT}$ & $2.67 \pm 0.10$ & $2.55 \pm 0.40$ & $0.179 \pm 0.012$ & $0.205 \pm 0.038$ & 0.707 & 0.951 & 0.437 & 0.491 \\
\hline CFT & $2.69 \pm 0.12$ & $2.17 \pm 0.12$ & $0.182 \pm 0.013$ & $0.135 \pm 0.003$ & 0.209 & 0.519 & 0.938 & 0.608 \\
\hline
\end{tabular}

Significant $P$ values are highlighted as $P<0.1\left(^{*}\right), P<0.05\left(^{* *}\right), P<0.01\left(^{(* *}\right)$. 
fertilization and phosphorus concentration reduced in response to cutting and trampling (Table 2). Fertilization also increased phosphorus and, to lesser extent, nitrogen concentrations in Saussurea and trampling had negative effect on $\mathrm{N}$ concentration (Table 2).

The AM, yeast, and fine endophyte frequency remained stable across the simulated grazing treatments and the treatments did not affect AM or FE in Potentilla (Figure 2, Table 3). DSE frequency did not correlate with any other measured fungal parameter in the plant roots, but average Potentilla FE and AM frequency correlated with each other (FE-hyphae, $p=.047$; FE-arbuscules, $p=.06 ; N=40)$. Fertilization and trampling significantly increased DSE fungal frequency in Potentilla (Figure 2, Table 3). None of the treatments affected fungal colonization in Saussurea roots (Figure 3, Table 3).

\section{Discussion}

Herbivore management has been proposed as a tool to combat global climate change effects in cold climates (Olofsson and Post 2018). Knowledge on collective and individual plant responses is critical to successfully predict tundra ecosystem reactions to changes in herbivore pressure. The two common herbs studied responded to simulated grazing in a species-specific manner, highlighting the importance of species diversity within the herbaceous functional group. The diversity in common plant responses to trampling, cutting, and fertilization is not trivial because this translates into ecosystem functions through different biomass accumulation and nutrient concentration and therefore effects on herbivores (Cherif and Loreau 2013). Potentilla crantzii has been shown to benefit from cattle grazing (Pykälä 2005). The
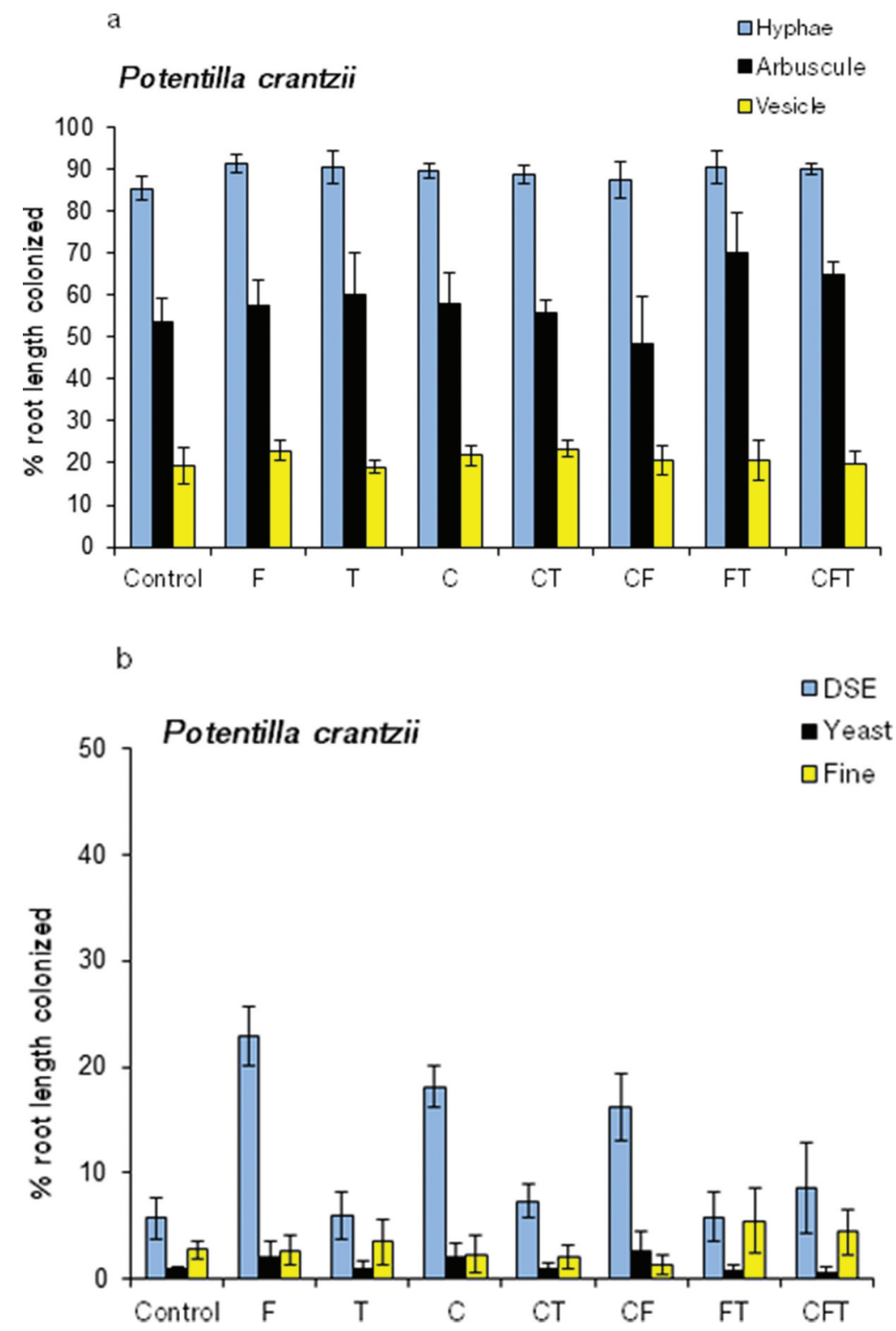

Figure 2. Average colonization frequency by (A) arbuscular fungal hyphae, arbuscules, and vesicles and (B) dark septate endophytes (DSE), yeast fungi (yeasts), and fine endophytes (FE) in the roots of Potentilla crantzii grown for three years in field plots exposed to the fertilization $(F)$, cutting $(C)$, and trampling $(T)$ treatments and their interactions $(N=40)$. 
Table 3. Probability values according to three factor ANOVA on AM hyphal (HYPHA), arbuscular (ARB), vesicular (VES), dark septate (DSE), yeast (YEAST) and fine endophyte (FE) colonization frequency in roots of Potentilla crantzii and Saussurea alpina. The plants were growing for three years in plots exposed to Fertilization, Trampling and Cut treatments in a fully factorial design ( $\mathrm{N}=40$ for Potentilla and 39 for Saussurea.

\begin{tabular}{|c|c|c|c|c|c|c|}
\hline \multicolumn{7}{|l|}{ Potentilla } \\
\hline & HYPHA & ARB & VES & DSE & YEAST & $\mathrm{FE}$ \\
\hline Fertilization & 0.475 & 0.514 & 0.992 & $0.037^{* *}$ & 0.916 & 0.601 \\
\hline Trampling & 0.510 & 0.117 & 0.837 & $<0.01^{* * *}$ & 0.196 & 0.372 \\
\hline Cut & 0.726 & 0.461 & 0.628 & 0.210 & 0.587 & 0.453 \\
\hline $\mathrm{CT}$ & 0.481 & 0.767 & 0.765 & 0.819 & 0.695 & 0.727 \\
\hline CF & 0.515 & 0.465 & 0.255 & $0.026^{* *}$ & 0.942 & 0.835 \\
\hline FT & 0.658 & 0.227 & 0.546 & $0.066^{*}$ & 0.728 & 0.263 \\
\hline CFT & 0.431 & 0.610 & 0.956 & $0.011^{* *}$ & 0.910 & 0.788 \\
\hline \multicolumn{7}{|l|}{ Saussurea } \\
\hline & \multicolumn{2}{|l|}{ HYPHA } & ARB & VES & DSE & YEAST \\
\hline Fertilization & 0.421 & \multicolumn{2}{|c|}{0.179} & 0.328 & 0.367 & 0.370 \\
\hline Trampling & 0.626 & \multicolumn{2}{|c|}{0.730} & 0.907 & 0.458 & 0.718 \\
\hline Cut & 0.233 & \multicolumn{2}{|c|}{$0.080^{*}$} & 0.277 & 0.917 & 0.660 \\
\hline $\mathrm{CT}$ & 0.859 & \multicolumn{2}{|c|}{0.461} & 0.859 & 0.604 & 0.442 \\
\hline $\mathrm{CF}$ & 0.461 & \multicolumn{2}{|c|}{0.365} & 0.300 & 0.456 & 0.549 \\
\hline $\mathrm{FT}$ & 0.339 & \multicolumn{2}{|c|}{0.218} & 0.382 & 0.567 & 0.663 \\
\hline CFT & 0.461 & \multicolumn{2}{|c|}{0.487} & 0.970 & 0.351 & 0.449 \\
\hline
\end{tabular}

Significant $P$ values are highlighted as $P<0.1\left(^{*}\right), P<0.05\left({ }^{* *}\right), P<0.01(* * *)$.

present work suggests that the positive effect of grazing on Potentilla may be due to removal of taller plants and reduced light competition. This is further supported by the decrease in Potentilla abundance in fertilized plots coinciding with higher overall plant biomass (Olofsson 2009). These results run counter those by Klanderud (2008) that fertilizing arctoalpine meadows increases Potentilla abundance and highlights the context dependency of plant responses. In contrast to Potentilla, Saussurea alpina abundance increases in sites protected from grazing (Vowles et al. 2017). The present work elucidates the mechanisms of grazing impact on this cold climate herb. Saussurea responses to the treatments suggest that it does not compensate for consumption by reindeer but would benefit from the improved nutrient availability associated with grazing.

Cold climate microbes and plants are both nutrient limited (Schimel and Bennett 2004), and moderate nutrient additions could have a positive effect on both in the longer term. AM frequency did not increase in plant roots when moderately fertilized, but plant nutrient concentrations did. This may indicate high efficiency of mycorrhizal fungi in transferring $\mathrm{N}$ and $\mathrm{P}$ to hosts in nutrient-poor systems. Alternatively, plant nutrient uptake was facilitated by other microbial associates or direct root uptake was enhanced. The latter scenario is unlikely because plant nutrient uptake is downregulated in the presence of mycorrhizas in their roots (Smith et al. 2011). Although plants and microbes are likely nutrient limited in the Arctic, there is an upper threshold of nutrient requirement. Additions exceeding critical threshold levels affect ecosystem functions (Pardo et al. 2011). Below critical levels, some parts of ecosystems may already respond to $\mathrm{N}$ addition. In our system, in contrast to the nonresponsive AM fungi, DSE fungal frequency in plant roots tracked the increase in nutrient availability in Potentilla, but not in Saussurea, roots. Previous experiments have also shown that DSE fungal frequency in arctic plants responds to variations in environmental conditions. Pietikäinen, Kytöviita, and Vuoti (2005) and Ruotsalainen and Eskelinen (2011) reported decreasing DSE fungal abundance in response to fertilization in Deschampsia flexuosa (Poaceae) and in Solidago virgaurea (Asteraceae) in the low Arctic, respectively. Fertilization doses were as high as $8 \mathrm{~g} \mathrm{~N} \mathrm{~m}^{2}$ per year in the experiment by Pietikäinen, Kytöviita, and Vuoti (2005) and $9.6 \mathrm{~g} \mathrm{~N} \mathrm{~m}^{2}$ per year in the experiment by Ruotsalainen and Eskelinen (2011), whereas in the present experiment only the natural amount expected from increased input from grazing was added $\left(2 \mathrm{~g} \mathrm{~N} \mathrm{~m}^{2}\right.$ annually). It is therefore possible that relatively sudden large increases in nutrient availability have a negative effect on root colonizing DSE fungi, whereas more moderate increases have a positive or neutral effect. Supporting the latter view, Kytöviita, Pietikäinen, and Fritze (2011) did not find DSE fungal colonization differences in low Arctic Solidago virgaurea when comparing two sites that differed naturally in nutrient availability. Interestingly, DSE frequency increased in the species that suffered from fertilization, Potentilla, but was not affected in Saussurea. The plant frequency responses did not mirror the nutrient status of the plants because $\mathrm{N}$ and $\mathrm{P}$ concentrations in plant tissues increased in a similar pattern in both species. Considering the very limited amount of data on DSE fungal abundance in plant roots under environmental manipulations, it is possible that these results are due to plant and fungal species-specific responses to increasing nutrient availability.

Defoliation should result in shortage of both plant photosynthates and plant nutrient capital. Therefore, it is not straightforward to link plant root fungal responses to resource allocation by the host (Heyde et al. 2019), particularly because the plant may have compensatory responses that increase resource acquisition rates (Oesterheld and McNaughton 1991). In support of our initial hypothesis, AM fungal frequency in plant roots did not respond to cutting. These results are supported by the frequent finding that AM colonization frequencies remain unaffected by cutting (Barto and Rillig 2010; Yang et al. 2018; Heyde et al. 2019). Pietikäinen, Kytöviita, and Vuoti (2005), working in a low Arctic meadow, showed that within a single growing season, cutting vegetation decreased DSE frequency in the grass Deschampsia flexuosa but did not affect the DSE 
a
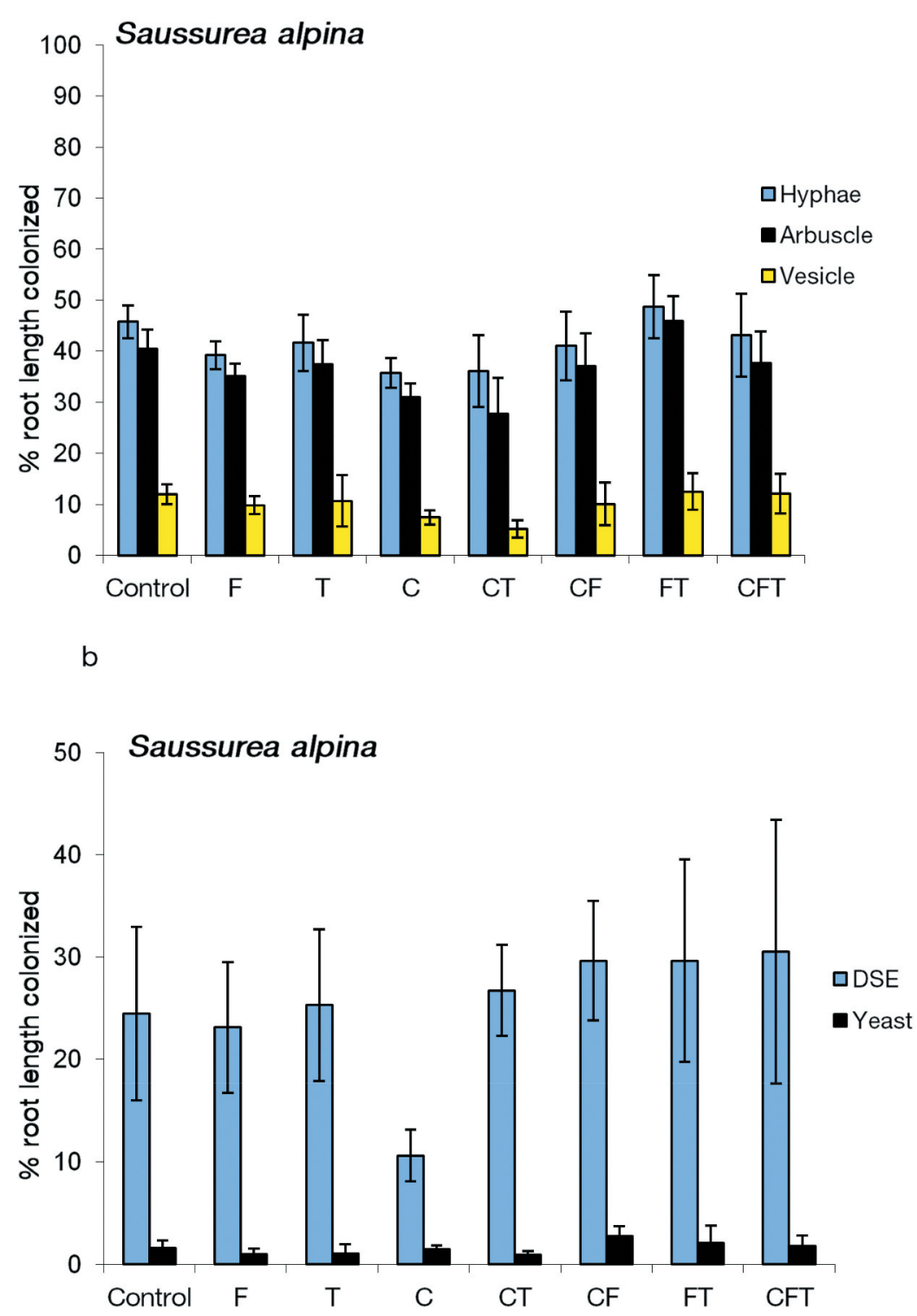

Figure 3. Average colonization frequency by (A) arbuscular fungal hyphae, arbuscules, and vesicles and (B) dark septate endophytes (DSE) and yeast fungi (yeasts) in the roots of Saussurea alpina grown for three years in field plots exposed to the fertilization (F), cutting $(\mathrm{C})$, and trampling $(\mathrm{T})$ treatments and their interactions $(N=39)$.

frequency in two herbaceous species (Solidago virgaurea and Trollius europaeus). Similarly, DSE frequency did not statistically significantly respond to clipping in either herb studied in this article. The variation in DSE colonization intensity varied notably between plots, which agrees with previous studies indicating that DSE colonization is sensitive to small-scale variation in soil conditions (Ruotsalainen and Eskelinen 2011).

Trampling is a disturbance associated with grazing that is rarely studied (Heggenes, Odland, and Bjerketvedt 2018). Trampling may damage roots (Olofsson 2009; Xu et al. 2012) and influence vegetation composition more strongly than intensive defoliation or fertilization (Egelkraut et al.
2020). In the present work, trampling reduced Saussurea nutrient acquisition, suggesting a belowground-mediated negative effect on the plant. Most studies on trampling effects focus on plant aboveground parts (Rosenthal, Schrautzer, and Eichberg 2012), but trampling may affect the ecosystem without visible aboveground effects as in the present case. Trampling compacts soil (Schrama et al. 2013) and may reduce soil microbial biomass (Sørensen et al. 2009) and activity (Schrama et al. 2013). There are very few reports on how trampling affects plant root fungal symbionts. In contrast to our initial hypothesis, trampling had no effect on AM fungal abundance in the plant roots. Similar to our results, trampling did not affect AM colonization in plant 
roots in the Mongolian steppe (Yang et al. 2018). We have previously shown that saprophytic fungal abundance decreased in the trampled plots in the present experiment and fertilization had no direct effect on saprophytic fungal abundance in the plots (Sørensen et al. 2009). These effects on saprophytic fungi were not mirrored in plant roots because fertilization and trampling increased DSE fungal frequency in Potentilla roots. This difference in soil fungi and root-inhabiting DSE could be explained by assuming that DSE fungi do not form such a large biomass in soil that their response would dominate the overall saprophytic fungal response or that the DSE fungal abundance in soil is not reflected in DSE fungal frequency in plant roots. Similar to a laboratory experiment with Medicago sativa (Saravesi, Ruotsalainen, and Cahill 2014) and a field experiment in arid steppe grasses (Garcia, Mendoza, and Pomar 2012), the DSE frequency in the plant roots increased in the treatments where the plant performance was reduced. These results show that DSE colonization may track changes in the environmental conditions, unalike AM fungi.

FE colonization was observed in Potentilla, but not in Saussurea, roots in this study. Similarly, FE colonized only Potentilla but not Solidago virgaurea or Alchemilla glomerulans in a low Arctic meadow in Kilpisjärvi, Finnish Lapland (Kytöviita, Pietikäinen, and Fritze 2011). This suggests a limited host range of FE fungi. FE colonization is common in some alpine meadows (Read and Haselwandter 1981; Müllen and Scmidt 1993). Read and Haselwandter (1981) suggested that FE colonization may be more common at high altitudes than at low altitudes. Zubek et al. (2009) noted that FE may be more common when competition by AM species is low. An AM species forming FE colonization has been shown to be a beneficial symbiont for plants (Powell 1979), and FE frequency may increase when plants are grown with low nutrient availability (Daft and Nicholson 1974; Rabatin 1979; Kytöviita, Pietikäinen, and Fritze 2011). In line with $\mathrm{AM}$ fungi, the $\mathrm{FE}$ frequency did not respond to simulated grazing in the present experiment, suggesting that they may be functionally similar. The abundance of staining filamentous Ascomycete fungi (i.e., Ascomycetes other than DSE fungi) and Basidiomycetes is very low $(<1$ percent frequency) in roots of low Arctic herbs (Pietikäinen, Kytöviita, and Vuoti 2005; Kytöviita, Pietikäinen, and Fritze 2011). However, unicellular yeasts belong to Ascomycota or Basidiomycota and may colonize up to 10 percent root length in low Arctic plants (Kytöviita, Pietikäinen, and Fritze 2011). In the present experiment, yeasts were discovered in roots of both target plant species, but their abundance was not affected by the simulated grazing. Endophytic yeasts have been shown to promote plant growth in crop plants (Joubert and Doty 2018). Recently, functional roles have been attributed to nonmycorrhizal fungi in arctic plant roots (Almario et al. 2017). It remains an open question whether and how the ubiquitous yeast colonization affects arctic host plants.

Teasing the interactive effects of a grazer (trampling, defoliation, and fertilization) apart showed that none of these affected AM fungal frequency in the two target species given singly or in factorial combinations. The present experiment was long enough (three years) for new roots to grow after initiation of the treatments and hence potentially for mycorrhiza-free roots to develop under field conditions even in slow-growing subarctic herbs. The fact that both target species retained a high frequency of arbuscules, the putative sites of resource exchange under simulated grazing, is strong evidence that AM mycorrhizas are an integral part of plant resource acquisition strategy when the plants experience herbivory and are growing in intensively trampled and moderately nutrient-enriched conditions. The idiosyncratic responses by DSE fungal frequency in the two host plants in our experiment indicate that the host plant identity has a pivotal role in the DSE fungus-plant outcome. DSE fungal frequency did not respond to environmental manipulations in a manner similar to arbuscular mycorrhizas, suggesting that they have different roles in plant ecology. Given the limited information on DSE fungal biology, DSE fungal frequency in a host plant's roots may be (1) determined by the host plant and changes in its physiology in response to the environment, (2) a result of DSE fungi responding directly to changes in the abiotic soil environment, or (3) a result of DSE fungi responding to the biotic soil environment. Novel experimental approaches are needed to elucidate these possibilities.

\section{Acknowledgments}

We thank the Oulu University technical team for help with the laboratory work and Abisko Research Station for help during fieldwork.

\section{Disclosure statement}

No potential conflict of interest was reported by the authors.

\section{ORCID}

Minna-Maarit Kytöviita (D) http://orcid.org/0000-0002-89286951

Johan Olofsson (iD http://orcid.org/0000-0002-6943-1218

\section{References}

Addy, H. D., M. M. Piercey, and R. S. Currah. 2005. Microfungal endophytes in plant roots. Canadian Journal of Botany 83:1-13. doi:10.1139/b04-171. 
Almario, J., G. Jeena, G. Wunder, W. Langen, A. Zuccaro, G. Coupland, and M. Buchera. 2017. Root-associated fungal microbiota of nonmycorrhizal Arabis alpina and its contribution to plant phosphorus nutrition. Proceedings of the National Academy of Sciences 114:E9403-12. doi:10.1073/ pnas.1710455114.

Augé, R. M. 2001. Water relations, drought and vesicular arbuscular mycorrhizal symbiosis. Mycorrhiza 11:3-42. doi:10.1007/s005720100097.

Barthelemy, H., S. Stark, and J. Olofsson. 2015. Strong responses of subarctic plant communities to long-term reindeer feces manipulation. Ecosystems 18:740-51. doi:10.1007/s10021-015-9856-y.

Barthelemy, H., S. Stark, M.-M. Kytöviita, and J. Olofsson. 2017. Grazing decreases N partitioning among coexisting plant species. Functional Ecology 31:2051-60. doi:10.1111/ 1365-2435.12917.

Barto, E. K., and M. C. Rillig. 2010. Does herbivory really suppress mycorrhiza? A meta-analysis. Journal of Ecology 98 (4):745-53. doi:10.1111/j.1365-2745.2010.01658.x.

Bethlenfalvay, G. J., and S. Dakessian. 1984. Grazing effects on mycorrhizal colonization and floristic composition of the vegetation on a semiarid range in northern Nevada. Journal of Range Management 37 (4):312-16. doi:10.2307/3898701.

Bidartondo, M. I., D. J. Read, J. M. Trappe, V. Merckx, R. Ligrone, and J. G. Duckett. 2011. The dawn of symbiosis between plants and fungi. Biology Letters 7 (4):574-77. doi:10.1098/ rsbl.2010.1203.

Brundrett, M. C. 2002. Coevolution of roots and mycorrhizas of land plants. New Phytologist 154 (2):275-326. doi:10 .1046/j.1469-8137.2002.00397.x.

Bueno de Mesquita, C., S. Sartwell, E. Ordemann, D. Porazinska, E. Farrer, A. King, M. Spasojevic, J. Smith, K. Suding, and S. Schmidt. 2018. Patterns of root colonization by arbuscular mycorrhizal fungi and dark septate endophytes across a mostly-unvegetated, high-elevation landscape. Fungal Ecology 36:63-74. doi:10.1016/j.funeco.2018.07.009.

Caldwell, B. A., A. Jumpponen, and J. M. Trappe. 2000. Utilization of major detrital substrates by dark-septate, root endophytes. Mycologia 92:230-32. doi:10.1080/ 00275514.2000 .12061149$.

Cherif, M., and M. Loreau. 2013. Plant - HerbivoreDecomposer stoichiometric mismatches and nutrient cycling in ecosystems. Proceedings of the Royal Society B: Biological Sciences 280:2012-453. doi:10.1098/rspb.2012.2453.

Corkidi, L., D. L. Rowland, N. C. Johnson, and E. B. Allen. 2002. Nitrogen fertilization alters the functioning of arbuscular mycorrhizas at two semiarid grasslands. Plant and Soil 240 (2):299-310. doi:10.1023/A:1015792204633.

Daft, J., and T. H. Nicholson. 1974. Arbuscular mycorrhizas in plants colonizing coal wastes in Scotland. New Phytologist 73:1129-38. doi:10.1111/j.1469-8137.1974.tb02142.x.

Desirò, A., J. Duckett, S. Pressel, J. Villarreal, and M. Bidartondo. 2013. Fungal symbioses in hornworts: A chequered history. Proceedings of the Royal Society B: Biological Sciences 280 (1759):20130207. doi:10.1098/ rspb.2013.0207.

Dhillion, S. S., and T. L. Gardsjord. 2004. Arbuscular mycorrhizas influence plant diversity, productivity, and nutrients in boreal grasslands. Canadian Journal of Botany 82 (1):104-14. doi:10.1139/b03-139.
Donkor, N. T., J. V. Gedir, R. J. Hudson, E. W. Bork, D. S. Chanasyk, and M. A. Naeth. 2002. Impacts of grazing systems on soil compaction and pasture production in Alberta. Canadian Journal of Soil Science 82 (1):1-8. doi:10.4141/S01-008.

Drigo, B., A. S. Pijl, H. Duyts, A. M. Kielak, H. A. Gamper, M. J. Houtekamer, H. T. S. Boschker, P. L. E. Bodelier, A. S. Whiteley, J. A. V. Veen, et al. 2010. Shifting carbon flow from roots into associated microbial communities in response to elevated atmospheric $\mathrm{CO}_{2}$. Proceedings of the National Academy of Sciences 107 (24):10938-42. doi:10.10 73/pnas.0912421107.

Egelkraut, D., H. Barthelemy, J. Olofsson, and D. Ward. 2020. Reindeer trampling promotes vegetation changes in tundra heathlands: Results from a simulation experiment. Journal of Vegetation Science 31 (3):476-86. doi:10.1111/jvs.12871.

Eisenhauer, N., A. Milcu, A. C. W. Sabais, H. Bessler, J. Brenner, C. Engels, B. Klarner, M. Maraun, S. Partsch, C. Roscher, et al. 2011. Plant diversity surpasses plant functional groups and plant productivity as driver of soil biota in the long term. PLoS ONE 6 (1):e16055. doi:10.1371/ journal.pone.0016055.

Eom, A.-H., G. W. T. Wilson, and D. C. Hartnett. 2001. Effects of ungulate grazers on arbuscular mycorrhizal symbiosis and fungal community structure in tallgrass prairie. Mycologia 93:233-42. doi:10.1080/00275514.2001.12063153.

Field, K., M. Bidartondo, W. Rimington, G. Hoysted, D. Beerling, D. Cameron, J. Duckett, J. Leake, and S. Pressel. 2019. Functional complementarity of ancient plant-fungal mutualisms: Contrasting nitrogen, phosphorus and carbon exchanges between mucoromycotina and glomeromycotina fungal symbionts of liverworts. New Phytologist 223:908-21. doi:10.1111/nph.15819.

Garcia, I., R. Mendoza, and M. Pomar. 2012. Arbuscular mycorrhizal symbiosis and dark septate endophytes under contrasting grazing modes in the Magellanic steppe of Tierra del Fuego. Agriculture, Ecosystems \& Environment 155:194-201. doi:10.1016/j.agee.2012.04.020.

Gehring, C., J. Wolf, and T. Theimer. 2002. Terrestrial vertebrates promote arbuscular mycorrhizal fungal diversity and inoculum potential in a rain forest. Ecology Letters 5:540-48. doi:10.1046/j.1461-0248.2002.00353.x.

Gehring, C., and T. Whitham. 2002. Mycorrhizae-herbivore interactions: Population and community consequences. In Mycorrhizal ecology, ed. M. G. A. Heijden and U. Sanders, 295-320. Springer-Verlag.

Gianinazzi-Pearson, V. G., D. Morandi, J. Dexheimer, and S. Gianinazzi. 1981. Ultrastructural and ultracytochemical features of a Glomus tenuis mycorrhiza. New Phytologist 88 (4):633-39. doi:10.1111/j.1469-8137.1981.tb01739.x.

Hall, I. R. 1977. Species and mycorrhizal infections of New Zealand endogonaceae. Transactions of the British Mycological Society 68:341-56. doi:10.1016/S0007-1536(7 7)80186-1.

Hartnett, D. C., and G. W. T. Wilson. 1999. Mycorrhizae influence plant community structure and diversity in tallgrass prairie. Ecology 80:1187-95. doi:10.1890/0012-9658(1999)080[1187:MIPCSA]2.0.CO;2.

Heggenes, J., A. Odland, and D. Bjerketvedt. 2018. Are trampling effects by wild tundra reindeer understudied? Rangifer 38:1-12. doi:10.7557/2.38.1.4121. 
Heinen, R., M. van der Sluijs, A. Biere, J. Harvey, and M. Bezemer. 2018. Plant community composition but not plant traits determine the outcome of soil legacy effects on plants and insects. Journal of Ecology 106:1217-29. doi:10.1111/1365-2745.12907.

Heyde, M., L. Abbott, C. Gehring, V. Kokkoris, and M. Hart. 2019. Reconciling disparate responses to grazing in the arbuscular mycorrhizal symbiosis. Rhizosphere 11:100167. doi:10.1016/j.rhisph.2019.100167.

Hoysted, G., A. Jacob, J. Kowal, P. Giesemann, M. Midartondo, J. Duckett, G. Gebauer, W. Rimington, S. Schornack, S. Pressel, et al. 2019. Mucoromycotina fine root endophyte fungi form nutritional mutualisms with vascular plants. Plant Physiology 181:565-77. doi:10.1104/pp.19.00729.

IBM Corp. 2016. IBM SPSS statistics for windows, Version 24.0. Armonk, NY: IBM Corp. https://www-01.ibm.com/ support/docview.wss?uid=swg21476197.

John, M. K. 1970. Colorimetric determination of phosphorus in soil and plant materials with ascorbic acid. Soil Science 109:214-20. doi:10.1097/00010694-197004000-00002.

Johnson, D., M. Krsek, E. Wellington, A. Stott, L. Cole, R. Bardgett, D. Read, and J. Leake. 2005. Soil invertebrates disrupt carbon flow through fungal networks. Science 309:1047. doi:10.1126/science.1114769.

Joubert, P., and S. Doty. 2018. Endophytic yeasts: Biology, ecology and applications. In Endophytes of forest trees, ed. A. Pirttilä and A. Frank, 3-14. Springer International Publishing AG.

Jumpponen, A. 2001. Dark septate endophytes - are they mycorrhizal? Mycorrhiza 11:207-11. doi:10.1007/s0057 20100112.

Klanderud, K. 2008. Species-specific responses of an alpine plant community under simulated environmental change. Journal of Vegetation Science 19:363-72. doi:10.3170/20088-18376.

Klironomos, J. N., J. McCune, M. Hart, and J. Neville. 2000. The influence of arbuscular mycorrhizae on the relationship between plant diversity and productivity. Ecology Letters 3:137-41. doi:10.1046/j.1461-0248.2000.00131.x.

Knapp, D. G., and G. M. Kovacs. 2016. Interspecific metabolic diversity of root-colonizing endophytic fungi revealed by enzyme activity tests. FEMS Microbiology Ecology 92:fiw190. doi:10.1093/femsec/fiw190.

Koide, R. T. 1991. Nutrient supply, nutrient demand and plant response to mycorrhizal infection. New Phytologist 117 (3):365-86. doi:10.1111/j.1469-8137.1991.tb00001.x.

Kos, M., M. Tuijl, J. de Roo, P. Mulder, and M. Bezemer. 2015. Species-specific plant-soil feedback effects on aboveground plant-insect interactions. Journal of Ecology 103:904-14. doi:10.1111/1365-2745.12402.

Kytöviita, M.-M. 2005. Asymmetric symbiont adaptation to Arctic conditions could explain why high Arctic plants are non-mycorrhizal. FEMS Microbiology Ecology 53 (1):27-32. doi:10.1016/j.femsec.2004.09.014.

Kytöviita, M.-M., A. Pietikäinen, and H. Fritze. 2011. Soil microbial and plant responses to absence of plant cover and monoculturing in low arctic meadows. Applied Soil Ecology 48:142-51. doi:10.1016/j.apsoil.2011.03.011.

Kytöviita, M.-M., and A. Ruotsalainen. 2007. Mycorrhizal benefit in two low arctic herbs increases with increasing temperature. American Journal of Botany 94:1309-15. doi:10.3732/ajb.94.8.1309.

Lu, X., and R. T. Koide. 1994. The effects of mycorrhizal infection on components of plant growth and reproduction. New Phytologist 128 (2):211-18. doi:10.11 11/j.1469-8137.1994.tb04004.x.

Lugo, M. A., M. E. G. Maza, and M. N. Cabello. 2003. Arbuscular mycorrhizal fungi in a mountain grassland. II. Seasonal variation of colonization studied, along with its relation to grazing and metabolic host type. Mycologia 95:407-15. doi:10.1080/15572536.2004.11833085.

Mandyam, K., and A. Jumpponen. 2005. Seeking the elusive function of the root-colonising dark septate endophytic fungi. Studies in Mycology 53:173-89. doi:10.3114/sim.53. 1.173 .

McGonigle, T. P., M. H. Miller, D. G. Evans, G. L. Fairchild, and J. A. Swan. 1990. A new method which gives an objective measure of colonization of roots by vesicular- arbuscular mycorrhizal fungi. New Phytologist 115:495-501. doi:10.1111/j.1469-8137.1990.tb00476.x.

Müllen, R. B., and S. K. Scmidt. 1993. Mycorrhizal infection, phosphorus uptake, and phenology in Ranunculus adoneus: implications for the functioning of mycorrhizae in alpine systems. Oecologia 94:229-34.

Munkvold, L., R. Kjøller, M. Vestberg, S. Rosendahl, and I. Jakobsen. 2004. High functional diversity within species of arbuscular mycorrhizal fungi. New Phytologist 164:357-64. doi:10.1111/j.1469-8137.2004.01169.x.

Murray, T. R., D. A. Frank, and C. A. Gehring. 2011. Ungulate and topographic control of arbuscular fungal spore community composition in a temperate grassland. Ecology 91:815-27. doi:10.1890/09-0209.1.

Newsham, K. K. 2011. A meta-analysis of plant responses to dark septate root endophytes. New Phytologist 190:783-93. doi:10.1111/j.1469-8137.2010.03611.x.

Newsham, K. K., R. Upson, and D. J. Read. 2009. Mycorrhizas and dark septate root endophytes in polar regions. Fungal Ecology 2:10-20. doi:10.1016/j.funeco. 2008.10.005.

Nuortila, C., M.-M. Kytöviita, and J. Tuomi. 2004. Mycorrhizal symbiosis has contrasting effects on fitness components in Campanula rotundifolia. New Phytologist 164:545-53. doi:10.1111/j.1469-8137.2004.01195.x.

Oesterheld, M., and S. J. McNaughton. 1991. Effect of defoliation upon root growth, phosphate absorption and respiration in nutrient-limited tundra graminoids. Oecologia 42:67-79.

Olofsson, J. 2009. Effects of simulated reindeer grazing, trampling, and waste products on nitrogen mineralization and primary production. Arctic, Antarctic, and Alpine Research 41:330-38. doi:10.1657/1938-4246-41.3.330.

Olofsson, J., and E. Post. 2018. Effects of large herbivores on tundra vegetation in a changing climate, and implications for rewilding. Philosophical Transactions of the Royal Society B: Biological Sciences 373:20170437. doi:10.1098/ rstb.2017.0437.

Olofsson, J., and H. Shams. 2007. Determinants of plant species richness in an alpine meadow. Journal of Ecology 95:916-25. doi:10.1111/j.1365-2745.2007.01284.x.

Olofsson, J., and L. Oksanen. 2002. Role of litter decomposition for the increased primary production in areas heavily 
grazed by reindeer: A litterbag experiment. Oikos 96:507-15. doi:10.1034/j.1600-0706.2002.960312.x.

Olofsson, J., S. Stark, and L. Oksanen. 2004. Reindeer influence on ecosystem processes in the tundra. Oikos 105:386-96. doi:10.1111/j.0030-1299.2004.13048.x.

Orchard, S., R. Standish, I. A. Dickie, M. Renton, C. Walker, D. Moot, and M. Ryan. 2017. Fine root endophytes under scrutiny: A review of the literature on arbuscule-producing fungi recently suggested to belong to the Mucoromycotina. Mycorrhiza 27:619-38. doi:10.1007/s00572-017-0782-z.

Orchard, S., S. Hilton, G. Bending, I. A. Dickie, R. Standish, D. Gleeson, R. Jeffery, J. Powell, C. Walker, D. Bass, et al. 2017. Fine endophytes (Glomus tenue) are related to Mucoromycotina, not Glomeromycota. New Phytologist 213:481-86. doi:10.1111/nph.14268.

Pardo, L. H., M. E. Fenn, C. L. Goodale, L. H. Geiser, C. T. Driscoll, E. B. Allen, J. S. Baron, R. Bobbink, W. D. Bowman, C. M. Clark, et al. 2011. Effects of nitrogen deposition and empirical nitrogen critical loads for ecoregions of the United States. Ecological Applications 21:3049-82. doi:10.1890/10-2341.1.

Phillips, J. M., and D. S. Hayman. 1970. Improved procedures for clearing roots and staining parasitic and vesicular-arbuscular mycorrhizal fungi for rapid assessment of infection. Transactions of the British Mycological Society 55:158-61. doi:10.1016/S0007-1536(70)80110-3.

Pietikäinen, A., and M.-M. Kytöviita. 2007. Defoliation changes mycorrhizal benefit and competitive interactions between seedlings and adult plant. Journal of Ecology 95:639-47. doi:10.1111/j.1365-2745.2007.01257.x.

Pietikäinen, A., M.-M. Kytöviita, and U. Vuoti. 2005. Mycorrhizal symbiosis and seedling establishment in a subarctic meadow: Effects of fertilization and clipping. Journal of Vegetation Science 16:175-82. doi:10.1111/ j.1654-1103.2005.tb02353.x.

Powell, C. L. L. 1979. Inoculation of white clover and ryegrass seed with mycorrhizal fungi. New Phytologist 83 (1):81-85. doi:10.1111/j.1469-8137.1979.tb00728.x.

Pozo, M. J., and C. Azcón-Aguilar. 2007. Unraveling mycorrhiza-induced resistance. Current Opinion in Plant Biology 10:393-98. doi:10.1016/j.pbi.2007.05.004.

Pykälä, J. 2005. Plant species responses to cattle grazing in mesic semi-natural grassland. Agriculture, Ecosystems \& Environment 108:109-17. doi:10.1016/j.agee.2005.01.012.

Rabatin, S. 1979. Seasonal and edaphic variation in vesicular-arbuscular mycorrhizal infection of grasses by Glomus tenuis. New Phytologist 83 (1):95-102. doi:10.11 11/j.1469-8137.1979.tb00730.x.

Ranelli, L., W. Hendricks, J. Lynn, S. Kivlin, and J. Rudgers. 2015. Biotic andabiotic predictors of fungal colonization in grasses of the Colorado Rockies. Diversity and Distributions 21:962e976. doi:10.1111/ddi.12310.

Read, D. J., and J. Perez-Moreno. 2003. Mycorrhizas and nutrient cycling in ecosystems - a journey towards relevance? New Phytologist 157:475-92. doi:10.1046/j.146 9-8137.2003.00704.x.

Read, D. J., and K. Haselwandter. 1981. Observations on the mycorrhizal status of some alpine plant communities. New Phytologist 88:341-52. doi:10.1111/j.1469-8137.1981. tb01729.x.

Riach, A., M. Perera, H. Florance, S. Penfield, and J. Hill. 2015. Analysis of plant leaf metabolites reveals no common response to insect herbivory by Pieris rapae in three related host-plant species. Journal of Experimental Botany 66 (9):2547-56. doi:10.1093/jxb/erv045.

Richards, L., I. Dyer, M. Forister, A. Smilanich, C. Dodson, M. Leonard, and C. Jeffrey. 2015. Phytochemical diversity drives plant-insect community diversity. Proceedings of the National Academy of Sciences 112:10973-78. doi:10.1073/ pnas. 1504977112.

Rosenthal, G., J. Schrautzer, and C. Eichberg. 2012. Lowintensity grazing with domestic herbivores: A tool for maintaining and restoring plant diversity in temperate Europe. Tuexenia 167-205.

Ruotsalainen, A. L., and A. Eskelinen. 2011. Root fungal symbionts interact with above-ground mammalian herbivory, soil nutrient availability and specific habitat conditions. Oecologia 166:807-17. doi:10.1007/s00442-011-1928-x.

Ruotsalainen, A. L., and M.-M. Kytöviita. 2004. Mycorrhiza does not alter low temperature impact on Gnaphalium norvegicum. Oecologia 140:226-33. doi:10.1007/s00442-004-1586-3.

Saravesi, K., A.-L. Ruotsalainen, and J. Cahill. 2014. Contrasting impacts of defoliation on root colonization by arbuscular mycorrhizal and dark septate endophytic of Medicago sativa. Mycorrhiza 24:239-45. doi:10.1007/s00572-013-0536-5.

Scheublin, T. R., R. S. P. van Logtestijn, and M. G. A. van der Heijden. 2007. Presence and identity of arbuscular mycorrhizal fungi influence competitive interactions between plant species. Journal of Ecology 95:631-38. doi:10.1111/ j.1365-2745.2007.01244.x.

Schimel, J. P., and J. Bennett. 2004. Nitrogen mineralization: Challenges of a changing paradigm. Ecology 85:591-602. doi:10.1890/03-8002.

Schrama, M., P. Heijning, J. Bakker, H. van Wijnen, P. Berg, and H. Olff. 2013. Herbivore trampling as an alternative pathway for explaining differences in nitrogen mineralization in moist grasslands. Oecologia 172:231-43. doi:10.100 7/s00442-012-2484-8.

Skjenneberg, S., and L. Slagsvold. 1968. Reindeer husbandry and its natural basis. Bergen, Tromsö: Universitetsförlaget Oslo. (in Norwegian).

Smith, S. E., I. Jakobsen, M. Grønlund, and F. A. Smith. 2011. Roles of arbuscular mycorrhizas in plant phosphorus nutrition: Interactions between pathways of phosphorus uptake in arbuscular mycorrhizal roots have important implications for understanding and manipulating plant phosphorus acquisition. Plant Physiology 156 (3):1050-57. doi:10.1104/pp.111.174581.

Sørensen, L., J. Mikola, M.-M. Kytöviita, and J. Olofsson. 2009. Trampling and spatial heterogeneity explain decomposer abundances in a sub-arctic grassland subjected to simulated reindeer grazing. Ecosystems 12:830-42. doi:10.1007/ s10021-009-9260-6.

Treseder, K., and M. Allen. 2002. Direct nitrogen and phosphorus limitation of arbuscular mycorrhizal fungi: A model and field test. New Phytologist 108 (3):109-17. doi:10.1046/ j.1469-8137.2002.00470.x.

Tuomi, J., M.-M. Kytöviita, and R. Härdling. 2001. Costefficiency of nutrient acquisition and advantage of mycorrhizal symbiosis for the host plant. Oikos 92:62-70. doi:10.1034/j.1600-0706.2001.920108.x.

van der Wal, R. 2006. Do herbivores cause habitat degradation or vegetation state transition? Evidence from the tundra. Oikos 114:177-86. doi:10.1111/j.2006.0030-1299.14264.x. 
van der Wal, R., and R. W. Brooker. 2004. Mosses mediate grazer impacts on grass abundance in arctic ecosystems. Functional Ecology 157 (1):77-86. doi:10.1111/j.1365-2435.2004.00820.x.

Vowles, T., C. Lovehav, U. Molau, and R. Björk. 2017. Contrasting impacts of reindeer grazing in two tundra grasslands. Environmental Research Letters 66 (3):034018. doi:10.1088/ 1748-9326/aa62af.

Walker, C., A. Gollotte, and D. Redecker. 2018. A new genus, Planticonsortium (Mucoromycotina), and new combination (P. tenue), for the fine root endophyte, Glomus tenue (basionym Rhizophagus tenuis). Mycorrhiza 28:213-19. doi:10.1007/s005 72-017-0815-7.

Wang, B., and Y. L. Qiu. 2006. Phylogenetic distribution and evolution of mycorrhizas in land plants. Mycorrhiza 16:299-363. doi:10.1007/s00572-005-0033-6.
Xu, L., F.-H. Yu, E. van Drunen, F. Schieving, M. Dong, and N. Anten. 2012. Trampling, defoliation and physiological integration affect growth, morphological and mechanical properties of a root-suckering clonal tree. Annals of Botany 109:1001-08. doi:10.1093/aob/mcs0 06.

Yang, X., Y. Shen, N. Liu, G. Wilson, A. Cobb, and Y. Zhang. 2018. Defoliation and arbuscular mycorrhizal fungi shape plant communities in overgrazed semiarid grasslands. Ecology 99:1847-56.

Zubek, S., J. Blaszkowski, A. Delimat, and K. Turnau. 2009. Arbuscular mycorrhizal and dark septate endophyte colonization along altitudinal gradients in the Tatra Mountains. Arctic, Antarctic, and Alpine Research 41 (2):272-79. doi:10.1657/1938-4246-41.2.272. 